\title{
Positive Psychology Progress in India: Accomplishments and Pathways Ahead
}

\section{Anindita Ghosh \& Amrita Deb}

\section{Psychological Studies}

ISSN 0033-2968

Volume 61

Number 3

Psychol Stud (2016) 61:113-125

DOI 10.1007/s12646-016-0367-5

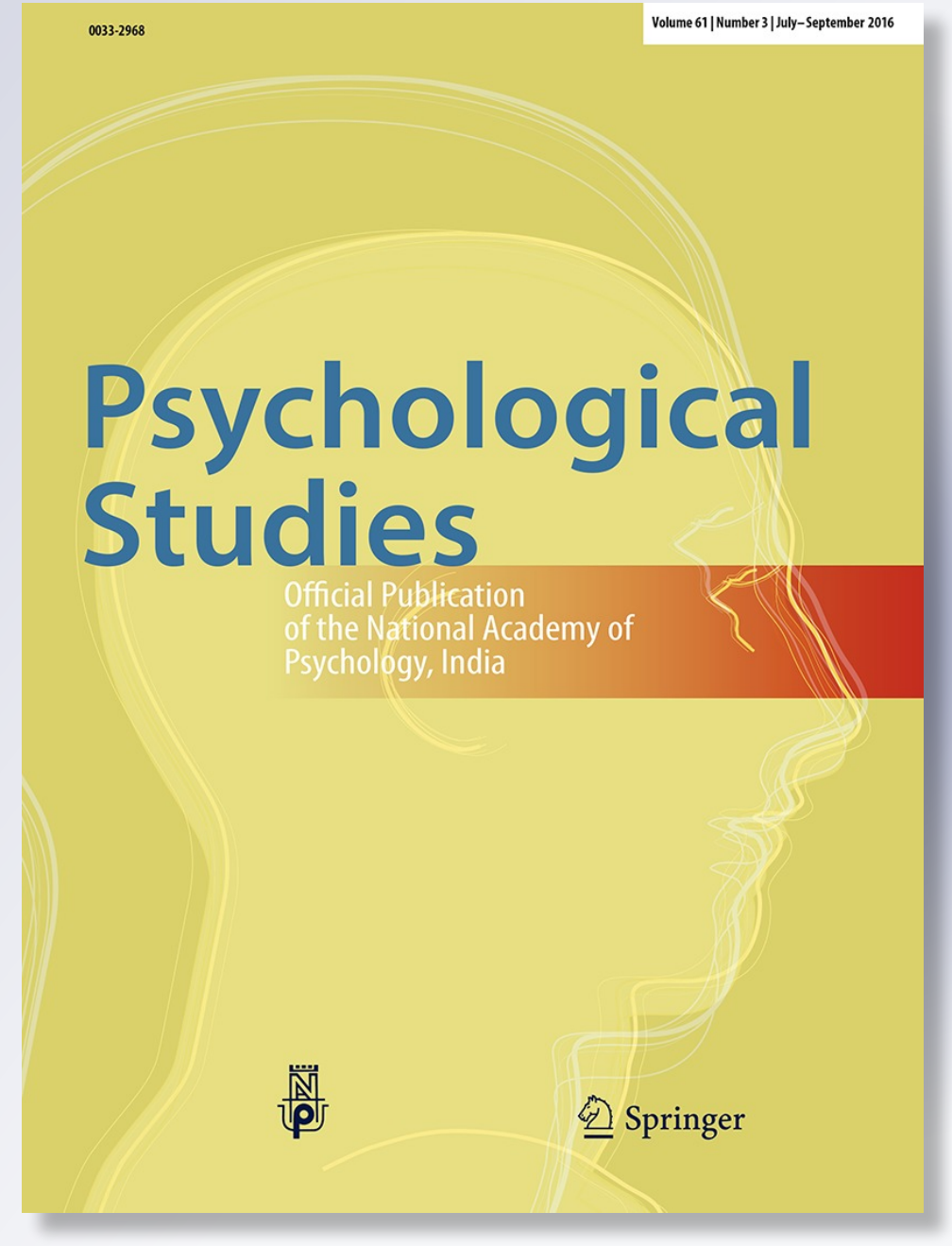

望 Springer 
Your article is protected by copyright and all rights are held exclusively by National Academy of Psychology (NAOP) India. This eoffprint is for personal use only and shall not be self-archived in electronic repositories. If you wish to self-archive your article, please use the accepted manuscript version for posting on your own website. You may further deposit the accepted manuscript version in any repository, provided it is only made publicly available 12 months after official publication or later and provided acknowledgement is given to the original source of publication and a link is inserted to the published article on Springer's website. The link must be accompanied by the following text: "The final publication is available at link.springer.com". 


\title{
Positive Psychology Progress in India: Accomplishments and Pathways Ahead
}

\author{
Anindita Ghosh ${ }^{1} \cdot$ Amrita Deb $^{1}$
}

Received: 6 April 2015/Accepted: 29 August 2016/Published online: 15 September 2016

(C) National Academy of Psychology (NAOP) India 2016

\begin{abstract}
The aim of this study is to summarize the developments in the field of positive psychology in India by focusing on research and applications. Since the emergence of the positive psychology movement in the West in 1998, researchers worldwide including India have been influenced by its strength-based approach. Over time, positive psychology in India has garnered an empirical base. This paper attempts to trace the development of the field within India. Various databases such as PsycINFO, Science Direct, PubMed, EBSCO and Shodhganga were searched along with the gray literature according to a set of criteria. Relevant researches were categorized under study characteristics, variables studied and assessment of positive psychology variables. Findings show that well-being is the most widely studied topic in positive psychology in India. Other topics including character strengths and posttraumatic growth also seem to be gaining popularity. Future directions on investigating topics that have not received adequate attention, making efforts to bridge the gap between Indian psychology and positive psychology, addressing cultural issues in positive psychology research, focusing on interdisciplinary and multi-method approach and finally making positive psychology available to the non-scientific community, have been provided. It is hoped that these efforts will enable us to build a positive psychology community. On the basis of this analysis, it may be derived that psychology research in India has started focusing on prevention along with cure.
\end{abstract}

Anindita Ghosh

la14resch01001@iith.ac.in

1 Department of Liberal Arts, Indian Institute of Technology Hyderabad, Sangareddy, Telangana, India
Keywords Positive psychology in India · Well-being · Strength-based approach · Positive mental health

The positive psychology (PP) movement emphasizes on studying strengths rather than weaknesses thus bringing focus on prevention along with cure. Since the emergence of the positive psychology movement in the West in 1998, researchers worldwide including India have been influenced by its strength-based approach. Seligman, Steen, and Peterson (2005a) in tracing the progress of PP commented that it has "flourished in the last 5 years" (p. 1). This comment was made a decade back; since then there has been an expeditious growth in PP research across the globe including India. The aim of this paper is to understand whether PP is flourishing within India, the areas where more research is required and detect contradictory findings if any and provide future directions.

A recent World Health Organization (WHO) report (2012), declared that India accounted for the highest number of suicides in the world (PTI, 2014) with 84 suicides occurring per day due to family problems on an average (Pereira, 2013). Suicides were reportedly highest in the age group of 15-29 years (BS Reporter, 2014) which represents adolescence and early adulthood. Another report highlights that the IT sector, which though high paying is also extremely stressful with their employees seeking counseling more often than other professionals and their suicide rates rising by $8-10 \%$ from 2009 to 2013 (Banerjee, 2013). India also has the highest rate of major depression in the world (Chatterjee, 2011). These reflect poorly on the mental health condition of the country. Considering that mental health problems are on the rise and that India faces a severe crisis of psychiatrists which is expected to increase with time (Thirunavukarasu \& 
Thirunavukarasu, 2010), it may be suggested that focusing on prevention along with cure may be a practical way to deal with this crisis. Prevention was one of the main objectives of psychologists earlier but after World War II, psychology became limited to healing and repairing symptoms (Seligman \& Csikszentmihalyi, 2000). This very pessimistic and negative approach to psychology, called the deficit-based approach or the disease model became the dominant mental health paradigm. However, psychologists in the previous decade were increasingly becoming concerned with the "issue of prevention" (Seligman \& Csikszentmihalyi, 2000, p. 7). According to the WHO (2014), health is more than just the absence of illness (WHO, 2014). Thus, simply trying to fix what is wrong to achieve absence of illness does not lead to overall well-being. A need was therefore felt to move on to a strength-based model to leverage what is good in a person. Systematically building competency and enhancing human strengths were identified as the focus of prevention researchers. This was realized through the PP movement which can be traced to Seligman's 1998 APA presidential speech where he urged the scientific community to work together to harness the positive aspects of human beings and to help people live more fulfilling lives, at the subjective, individual and group level.

This perspective of looking at the positive in people and helping them achieving optimal functioning is not completely new. The humanistic movement with pioneers such as Abraham Maslow and Carl Rogers had already initiated studies on self-actualization, personal growth, and selfworth-all characteristics of the fully functioning person. But, "humanistic psychology did not attract much of a cumulative empirical base" (Seligman \& Csikszentmihalyi, 2000, p. 7). Aristotle, the Greek philosopher, had already introduced the terms hedonism and eudaimonism which Seligman (2002) later incorporated into his Authentic Happiness theory.

PP may learn a lot from Indian Psychology (IP) which is derived from ancient Indian texts and has received increasing attention from researchers in recent times. A long history of civilization makes the Indian socio-cultural diaspora an interesting aspect of study. Some recent articles have used concepts from IP and PP together to answer common questions about human life (for example, Cornelissen, 2014; Rao, 2014; Salagame, 2014). This endeavor can be understood in the light of Linley and Leontiev's (2009) observation that, when certain cultural frontiers are traversed, one may find "there is much in positive psychology that has been learned before, and from which positive psychology can learn again" (p. 258). Examples in favor of this argument may be presented through IP concepts similar to PP literature. For instance, various texts of the Vedas explain happiness as being subjective, not the absence of unhappiness, the primary motivator, a psychological state, which helps maintain interconnections with others, gives us the freedom to choose, and is realizable (Banavathy \& Choudry, 2014). Furthermore, there are writings about happiness in the Taittiriya Upanishad, where the self (atman or chitta) is enveloped in five layers or koshas (Shrivastava \& Misra, 2011) and distinctions have been made about different kinds of happiness and momentary pleasures in Eastern thought traditions (Misra, 2014; Shrivastava \& Misra, 2011). Evidence of the importance placed on happiness and thriving in Indian history and culture is reflected in common salutations used in everyday life such as "khush raho" (stay happy) (Shrivastava \& Misra, 2011). In addition to this, concepts such as the "guna theory" may be considered very similar to what is now referred to as the study of character strengths in PP. Eastern thought traditions of Hinduism, Buddhism and Jainism have long advocated the maintenance of a balance by accepting suffering as a part of life (Misra, 2014). This has only recently been popularized by PP through Seligman $(2002,2011)$ and Shahar (2013) that negative feelings are as much a part of life as positive ones. Thus, PP research is intended to supplement, not replace human "suffering, weakness and disorder" (Seligman, Steen, Park, \& Peterson, 2005b, p. 2).

$\mathrm{PP}$ as a field of study has been evolving rapidly since its inception. The special issue of the American Psychologist (2000) dedicated to PP published 16 articles outlining subject areas concerning PP. More recently in India, a special issue on PP by Psychological Studies (2014), has attempted to draw parallels between IP and PP so as to bring attention to those areas that still need to be traversed. Rao's target article on how PP and IP need to reinforce each other, generated responses from Cornelissen (2014), Dalal (2014), Salagame (2014), and others on the similarities and dissimilarities between IP and PP and the problems faced (Mehrotra, 2014). Other topics embraced were Vedantic perspective of happiness (Banavathy \& Choudry, 2014), positive emotions and cognitive flexibility (Nath \& Pradhan, 2014), exceptional mental states and psychological well-being (Pirta, 2014) and well-being of rural women (Singh, Kaur, Singh, \& Junnarkar, 2014). Thus, the emergence of PP in the West and attempts to draw parallels with IP concepts, makes it important for PP research in India to consider cultural components more critically to be able to widen its range of applicability.

The rationale for this study has been derived on the basis of information gleaned from the above discussion that highlights the emergence of the PP movement, the present mental health scenario and cultural context of India. Although certain features of PP were already a part of IP work in India, it is evident that the PP movement in the West has definitely added momentum to this research. The 
aim of this review is to therefore summarize the developments in research and application in India under the influence of this PP movement. It is expected that this will help to separate what is known from the unknown to plan the future course of action.

\section{Methodology}

A comprehensive search was conducted to trace the PP literature including but not limited to material on strengths based approaches (versus a deficit based approach) or mention of "positive psychology" as a keyword or studies by prominent positive psychologists. Tighter boundaries were ameliorated for the present review and researches were required to accede to all the following criteria: (a) conducted since 1998, which marks the beginning of the PP movement (b) conducted in India (c) written in English (d) linked to PP movement. These criteria were formulated in accordance with Seligman \& Csikszentmihalyi's (2000) definition of PP and Donaldson, Dollwet and Rao's (2014) suggestion that researches involving PP variables conducted before 1998 and without explicit reference to PP or linkage to PP movement need to be excluded in order to specifically study the progress of PP.

Major databases such as PsycINFO, Science Direct, PubMed, EBSCO and Shodhganga were searched to locate publications between 1998 and March 2015. Each search word was explored one at a time in combination with "positive psychology" and "India."

Few papers were rejected at the onset by scanning their titles. Apropos papers were further scrutinized using new keywords such as names of some pioneer researchers of PP like Seligman to check for linkages to PP movement and literature. Names of PP researchers in India that were obtained during the literature search were added to the initial keywords, and these were used as keywords further as displayed in Table 1. The snowballing technique (Ridley, 2012) was applied to go through the references of relevant articles. This process helped to locate more papers as well as identify researchers working in this area whose websites were then referred to for more articles. Some papers that were not available online were recovered by sending individual e-mails to authors. Duplicate search results, papers not in English, published before 1998 and with inadequate description about sample, tools and design were rejected. For example, papers relating self-efficacy to positive outcomes published before 1998 were not included. The search process also included examination of gray literature. Gray literature is "any document that is not an academic journal article...is not formally published...written for a restricted audience and so is less easily available" (Jesson, Matheson, \& Lacey, 2013, p. 54). The initial keywords were re-typed in Google in order to collect the literature which had not been published in journals covered by the databases mentioned above, including conference papers, working papers, commissioned research reports and thesis works. This process led to prolific results indicative of the level of interest that the strength-based model has generated overtime.

\section{Results and Discussion}

Among the books, theses, journal articles and other sources that were the outcome of the search, works that fit the criteria have been analyzed on the basis on their objectives, methodology, and results. The plethora of information has been presented under the broad categories of study characteristics, variables studied and assessment of PP variables. Implications and suggestions for future research have been discussed.

\section{Study Characteristics}

This review revealed that theoretical, research, and practice focused works have been conducted by PP researchers in India. These were both quantitative and qualitative in nature, comprising of cross-sectional and longitudinal works. While most have been published in peer-reviewed journals, few are theses. College students were the most studied sample. Also, studies particularly focusing on

Table 1 Sample search words used

\begin{tabular}{|c|c|c|c|}
\hline & & and & or \\
\hline $\begin{array}{l}\text { Step } \\
\text { I }\end{array}$ & $\begin{array}{l}\text { While searching titles and } \\
\text { abstracts in journals }\end{array}$ & $\begin{array}{l}\text { Positive } \\
\text { psychology, } \\
\text { India }\end{array}$ & Research, study, happiness, well-being \\
\hline $\begin{array}{l}\text { Step } \\
\text { II }\end{array}$ & While searching in-text & $\begin{array}{l}\text { Positive } \\
\text { psychology, } \\
\text { India }\end{array}$ & $\begin{array}{l}\text { Happiness, well-being, positive affect, positive } \\
\text { emotions, life satisfaction, subjective well-being, } \\
\text { psychological well-being, gratitude, grit, humor } \\
\text { Seligman, Lyubomirsky, Diener, Emmons, Deci, } \\
\text { Ryan, Singh, Misra }\end{array}$ \\
\hline
\end{tabular}


women have been carried out. Broad areas in which publications were discovered include health, rehabilitation, organizational behavior, IP and spirituality, developmental psychology and psychometrics. Subjective well-being (SWB), positive affect, life satisfaction, resilience, psychological capital, happiness and character strengths appear to be the most popularly studied topics.

\section{Variables Studied}

\section{Well-Being and Related Concepts}

Well-being has been studied as an outcome variable in many PP investigations. However, it still remains an elusive concept with even The Encyclopedia of Positive Psychology (Lopez, 2009) describing it only in terms of its historical roots instead of providing a uniquely agreed upon definition. Well-being has overlaps with several concepts like SWB, happiness (Diener, 1984; Peterson, 2007), emotional well-being (Peterson, 2007) quality of life and life satisfaction (Diener, 1984). This can also be observed in the studies discussed below.

One group of studies looked at positive affect as an indicator of well-being. Nath and Pradhan (2011) proposed a framework to study how positive writing affects wellbeing and physical health using concepts from Fredrickson's (1998) broaden and build theory and by Aspinwall's (1998) self-regulation theory (as cited by Nath \& Pradhan, 2011). Pradhan and Nath (2011) further conclude that positive emotions are important for growth and development of human beings. Engaging in the activities of positive writing repeatedly, provides us with a better understanding of the environment and may lead to selfregulation (Nath \& Pradhan, 2011). Higher levels of positive affect increases psychological resilience which in turn improves physical health and psychological well-being (PWB) (Nath \& Pradhan, 2011; Nath \& Pradhan, 2012). Positive emotions enable flexible cognition, which increases perception about self-capacity and the situation (Nath $\&$ Pradhan, 2011). But contrarily, in an experimental study, induction of positive emotions did not increase cognitive flexibility (Nath \& Pradhan, 2014). Swaminath and Rao (2010) summarize from various researches that positive emotions physiologically down-regulate lingering negative emotions, broadens momentary thought which not only improves the ways people cope during crises and but also helps build physical, social, intellectual and psychological resources for an individual. Khosla and Dokania (2010) also found that happier individuals both women and men have higher emotional intelligence than unhappy women or men.

Another group of studies looked at positive physical and/or mental health as well-being. For instance, Peltzer and Pengpid (2013) testified that positive health behaviors were associated with happiness in university students and suggested that these relations could be bidirectional. This is similar to Lyubomirsky, King and Diener's (2005) study that reported a bidirectional relationship between happiness and success. Peltzer and Pengpid (2013) further observed that greater social support, personal mastery and higher socioeconomic status lead to greater happiness. On the same note, Yadav, Koushal, Aggarwal, Saini and Sharma (2012) believe that the interconnection between mental and physical health can be used to harness positive feelings through exercise and physical actions to reach goals in order to enhance them. Thus, it may be deduced that positive emotions can act as buffers against negative health outcomes (Swaminath \& Rao, 2010).

Some researchers have looked at meaningfulness in life as an indicator of well-being. This idea originates from Seligman's $(2002,2011)$ theories of Authentic Happiness and Flourish. Research in India has shown that meaning in life (Mathur \& Sharma, 2014; Pinjarkar \& Mehrotra, 2014) and a sense of coherence (Pinjarkar \& Mehrotra, 2014) are associated with higher well-being. Contrarily, there is also evidence to indicate that the search for meaning in life leads to experience of negative affect (Pinjarkar \& Mehrotra, 2014) and lower levels of well-being (Mathur \& Sharma, 2014). Pinjarkar and Mehrotra (2014) found that variables that predict meaning in life are more affective in nature rather than cognitive such as being loved, accepted and trusted by significant others. They also observed that women experienced more meaning from relationships and men from personal growth and having prestige in society. Biswas-Diener and Diener (2001) also observed that slum dwellers in India were more satisfied in their lives as the derived more meaning from their relationships with others.

Life satisfaction has also been studied as a synonym of well-being. Singh and Jha (2008) found that grit, positive affect, happiness and life satisfaction are all significantly positively correlated and that experience of negative affect decreases life satisfaction, happiness, and grit. Mukherjee, Nargundkar and Manjaly (2014) suggest on the basis of their findings that judgments about life satisfaction are lowered in presence of money where there is ambiguity and uncertainty about future.

Religion and spirituality are at many times considered to be paths to achieve well-being. Ramesh, Sathian, Sinu, and Rai (2013) found that Brahma Kumaris Rajayoga Meditation significantly increases an individual's self-satisfaction and happiness by enhancing positive thinking in them. This may be explained through Pirta's (2014) observation that exceptional mental states such as transcendence, "have significance for psychological well-being" (p. 166). But Peltzer and Pengpid (2013) found that religiousness and religious activities did not affect happiness of university 
students. Also, Kumar and Kumar (2013) equate karma yoga as defined in Gita, with flow. Flow as defined in PP is an intrinsic motivational state that gives pleasure through engagement with work. Experiencing flow leads to an increase in life satisfaction, positive affect and satisfaction with self (an indicator of happiness) for both genders while decreasing the experience of negative affect (Sahoo \& Sahu, 2009). Kumar and Kumar (2013) suggest that Karma yoga maybe used to reduce depression related anxiety and apprehension associated with work.

The idea that certain personality traits could help us achieve well-being has also been explored. Direct links between personality, emotional intelligence, and happiness and personality variables except agreeableness were reported among university students (Hafen, Singh, \& Laursen, 2011). Among students of professional courses, agreeableness as opposed to extraversion was found to be more associated with PWB (Singh, Singh, \& Singh, 2012); hope as a trait also influenced PWB positively. Furthermore, emotional intelligence and extraversion play a major role in predicting happiness for women in India. Similarly, there is a relation between traits related to extraversion and high levels of happiness in children (Holder, Coleman, \& Singh, 2012). This study on public school children in North India, found that higher levels of sociability, more activity and low levels of shyness were associated with being happier. These did not confirm the findings from a North American sample where neuroticism and happiness were found to be related. It was thus propounded that relations between temperament and happiness in children may not completely generalize across cultures. A high correlation was also found between resilience and extraversion and positive affect (Singh \& Yu, 2010).

Demographic variables such as age, gender, and education seem to play an important role in an individual's well-being. Singh, Ruch, and Junnarkar (2014) in an investigation with demographic variables found that adolescents who resided in rural areas and those who attended private school displayed higher levels of well-being than those living in urban areas and those attending public schools. Age, education, and work category did not significantly influence life satisfaction (cognitive component of SWB), whereas affect (emotional component) was influenced by the level of education among rural women (Singh, Kaur, Singh, \& Junnarkar, 2014). Another interesting finding was that well-being declined as age increased from early adolescence to middle adolescence to late adolescence (Sood \& Gupta, 2012; Singh, Ruch, \& Junnarkar, 2014). Thus, it may be concluded that wellbeing declines with increasing age. This may be attributed to higher levels of responsibility and along with it the stress that adults have to face. But Peltzer and Pengpid's (2013) found that age and gender were not associated with happiness among university students. Singh, Kaur, Singh, and Junnarkar (2014) found that among rural women, higher education led to better subjective and psychological well-being and positive relations with others as compared to those with lesser education. This is because it provides them with a better social standing in the society. More research is needed for arriving at conclusive findings to understand what influences well-being in different samples.

\section{Character Strengths}

A strength is the ability to think, feel, and behave in ways that allows a person to have optimal functioning to attain valued outcomes (Linley \& Harrington, 2006). Seligman (2002) explains how well-being can be attained by increasing strengths. The 24 character strengths proposed by Peterson and Seligman (2004) were listed as being ubiquitous across cultures (Peterson, 2007). In India, of these, only few strengths have received attention like leadership, gratitude, and forgiveness. Singh and Choubisa (2009a) commented that there could be cultural differences in the "development, prescription, and propagation" ( $p$. 67) of character strengths. Choubisa and Singh (2011) found solely three studies measuring the empirical structure of the character strength classification of VIA conducted globally before their own. Upon measuring the empirical structure of the character strength classification of VIA on an Indian sample, Singh and Choubisa (2010) found that original English version threw up only five factors. More surprisingly, Singh and Choubisa (2009a) found that the Hindi translated version supported only a one factor structure for the strengths. They have suggested the presence of a master strength that controls the overt expression of all the other strengths. These have been explained by the strengths being proposed from a ubiquitous theoretical point of view and not a statistical or empirical perspective and global influence. An indigenized version on VIA revealed that among young adults, men displayed higher social strengths like curiosity, leadership and courage while women displayed higher relational strengths like close loving relationships, gratitude, and thankfulness among others (Mehrotra, Tripathi \& Banu, 2015). Singh and Duggal (2012) also found that personality characteristics of agreeableness and conscientiousness and openness showed a significant positive relationship, while neuroticism showed a significant negative relationship with all of the six virtues in VIA. Singh (2010) mentions that most village girls in India value strengths that are different from the VIA strengths, such as being dutiful, empathetic, respecting elders, belief in God and patriotism. Also, girls and boys possessed all the character strengths, but the former were higher on forgiveness as compared to boys. A higher level of forgiveness and gratitude leads to higher 
levels of subjective well-being among adolescents (Magesh, Shruti, \& Divya, 2014). Contradictory findings show that well-being among adolescents, is not necessarily predicted by presence of gratitude (Sood \& Gupta, 2012). But in both studies (Magesh, Shruthi, \& Divya, 2014; Sood \& Gupta, 2012) no differences between adolescent boys and girls on forgiveness, gratitude and subjective wellbeing were found. The findings are explained by positing that in the Indian culture children are trained right from the beginning of their socialization process, to forgive and to express gratitude toward others regardless of gender.

\section{Growth After Adversity}

Growth after adversity is described as positive psychological change experienced as a result of the struggle with highly challenging life circumstances (Hussain \& Bhushan, 2013). For instance, relating to others, proactive coping and appreciation of life were important to lead to growth among tsunami relief volunteers (Bhushan \& Kumar, 2012). Similarly, among people living in poverty (slum dwellers, sex workers and homeless individuals living on the streets), who do not have access to many material necessities in life displayed much higher life satisfaction than expected in specific domains like satisfying relationships (Biswas-Diener \& Diener, 2001). In a comparative study between bereaved Indian and Japanese female college students, it was observed that Indian students were higher on resilience than their Japanese counterparts (Bhushan, Kumar, \& Harizuka, 2011). Positive reappraisal of the situation was found to facilitate the relation between resilience and pro-active coping while negative cognitions about the self, facilitated the relationship between resilience, proactive, and reflective coping. Nath and Pradhan (2013) reported that high extraversion and neuroticism reduces resilience as compared to low extraversion which strengthens resilience in college students. Additionally, only a moderate level of openness to experience shows the strongest effect on the relation between positive emotions and resilience. Furthermore, noticing positive emotions, and meaning finding helps in building psychological resilience. PP techniques were also instrumental in helping trafficked victims recover from trauma (Sharma \& Choudhary, 2013). Relation of PP variables with growth needs to be looked into in more detail.

\section{Positive Organizational Psychology}

Donaldson and Ko (2010) use the overarching term positive organizational psychology (POP) to refer to PP focused on work and organizational issues. In India, most studies in POP have been conducted on psychological capital (PsyCap). Gupta and Singh (2014) found that PsyCap (hope, optimism, resilience and self-efficacy) fully mediates the relationship between leadership and creativity in the $R \& D$ context. R\&D leaders who display behaviors of task-orientation, recognizing and inspiring, team building, empowering and leading by example, considered to be important by Indian employees helps employees develop PsyCap. This leads to increase in the employee's creativity. These behaviors can potentially impact their psychological capacities and eventually performance. Shahnawaz and Jafri (2009) found that even though PsyCap is important to be harnessed, it cannot in itself predict organizational commitment and organizational citizenship behavior. The organizational context, whether public or private also influences these two. On the other hand, Murthy (2014) found that PsyCap significantly increases organizational citizenship behavior of executives. Hasnain, Khan and Hasan (2013) found that happiness levels of private sector bank managers were higher than those in public sector. Further, happiness, organizational citizenship behavior and work motivation together acted as significant predictors of organizational commitment in managers of private sector banks but not in managers of public sector banks. PWB also fosters the development of organizational commitment among public sector employees (Rathi, 2011). Paul and Garg (2014) and Murthy (2014) suggest training employees in PsyCap. It will benefit human resource development, organizational effectiveness and facing challenges of globalization (Murthy, 2014). Major HRM challenges can be dealt by introducing the employees to experience subjective happiness while working by harnessing resilience in them (Paul \& Garg, 2014). Training can also be provided to enhance strengths and overcome weaknesses (Nath \& Pradhan, 2011).

\section{PP Interventions}

PP intervention may be understood as any intentional activity or method based on (a) the cultivation of valued subjective experiences, (b) the building of positive individual traits, or (c) the building of civic virtue and positive institutions (Meyers, Woerkom, \& Bakker, 2013). In India, PP interventions have so far been attempted in the areas of education, mental health, and rehabilitation. Singh and Choubisa (2009b) conducted a PP intervention using techniques like the three good things and the best possible selves exercise on students and found a significant increase in self-management, timeliness of task accomplishment and having written plans for the change. Choubisa (2011) developed a Web-based intervention to increase the wellbeing of college students. The "Feeling Good and Doing Well" intervention programme developed by Mehrotra, Elias, Chowdhury and Gupta (2013) has shown increases in SWB, PWB, self-efficacy in emotional regulation and goal 
pursuit and reduction in psychological distress among Indian college youth (Mehrotra, 2013). It focused on strengths, goals, best possible selves and relaxation strategies among others. Nath and Pradhan (2011) have suggested that positive writing can be used in education to help students regulate their emotions and deal with stress by developing psychological resilience, in counseling to enhance self-regulatory behavior, and in HRM to facilitate creative problem solving. But Nath and Pradhan (2014) in an experimental study that employed positive writing and watching a positive emotion inducing movie found that experience of positive emotions did not lead to cognitive flexibility in university students. These findings were explained through variables such as differences in personality and motivational factors.

Raje (2014) identified a need to strengthen the family of individuals diagnosed with mental illness, against dysfunction. A major process in the therapeutic transformation of a dysfunctional family involved Positive Psychotherapy (PPT). When PPT was clubbed with pharmacotherapy, the recovery rate was $85 \%$ and family mental health was achieved. The investigator explains that the experience of positive emotions through PPT promoted psychological resilience and positive emotional granularity among individuals. Another intervention by Lakshmanan and Mythili (n. d.) on early adolescent girls, included among other techniques yogic relaxation (alternative therapy), training on perseverance, developing positive values, so as to set new goals and purpose for life and generate new ideas about themselves. It led to an increase in resilience among students in the experimental group. Similarly, another PPT attempt by Sankaranarayanan and Cycil (2014) tested the effectiveness of the famous Penn Resiliency Program (PRP) on a sample of Indian urban early adolescents. A significant reduction in pessimistic explanatory style and an increase in optimistic orientation were found. Thus, the programme was able to change negative attributional styles in children. Yoga intervention studies by Pandit and Satish (2014) on preadolescent children reported improvement in health. PP techniques of sharing their life stories by looking at it from new and positive perspectives, keeping engaged in activities like dancing and sports, writing about positive experiences and strengths, using their strengths and writing about five things they are grateful for on a daily basis, helped in the rehabilitation of trafficked victims (Sharma \& Choudhary, 2013).

Malik and Singh (2012) provide a list of strategies for enhancing happiness in various domains of life such as spirituality, relationships with others, recreational activities and cognitive strategies. Singh (2010) suggests using an intervention program on college students in the classroom situation which involves introspection and retrospection. These techniques need to be further researched.

\section{Assessment of PP Variables}

The most commonly used measures in the studies reviewed were Positive Affect and Negative Affect Scale (Watson, Clark, \& Tellegen, 1988), Subjective Happiness Scale (Lyubomirsky \& Lepper, 1999), VIA (Peterson \& Seligman, 2004), Oxford Happiness Questionnaire (Hills \& Argyle, 2002), Connor-Davidson Resilience Scale (CDRISC; Campbell-Sills \& Sills, 2007), among others. Mehrotra and Tripathi's (2011) review points out that there is limited information about the measures used and their applicability in the Indian scenario in most studies. Singh and $\mathrm{Yu}$ (2010) observed that the reliability coefficient for CD-RISC was the same for an Indian population as that of the original sample, a four factor structure seemed to apply more as opposed to the original five factor structure.

Most questionnaires that have been used in Indian researches have been developed in non-Indian contexts. A few exceptions include a Hindi translated version for The Personal Well-being Index-school children (Cummins \& Lau, 2005) and VIA-IS (Park, Peterson, \& Seligman, 2004) that have been validated by Singh, Ruch and Junnarkar (2014) and translated by Singh and Choubisa (2009a), respectively. A vignette based measure on the 24 strengths of VIA was constructed by Mehrotra, Tripathi and Banu (2012) whereas a PsyCap questionnaire was developed by Gupta and Singh (2014) for the Indian population. Miret et al. (2012) constructed a shorter version on the Day Reconstruction Method (DRM), validated on Indian adults for measuring subjective well-being among large populations. Internet based mobile applications are already popular in the West. In India applications such as "mana maali" are currently being used to study selected PP variables among college students in Hyderabad, (https:// manamaali.wordpress.com). While efforts have been made to Indianize certain PP measures, further work in the area of PP assessment is needed for better understanding of these variables.

\section{Other Indicators of PP Progress}

The above section was an overview of progress made in research in India. However, some other indicators of growth of PP have also been discovered. Other than the special issue by Psychological Studies on PP, the Indian Journal of Positive Psychology has also been dedicated to further research in this area. Furthermore, few books like Positive Psychology: In The Light Of Indian Traditions and Flourishing Positivity in Young Women: An Intervention Study and many book chapters (for example, Kapur, 2013; Mehrotra \& Tripathi, 2013) have been published. Additionally, some institutes including IIT Delhi, IIT 
Hyderabad, NIMHANS, Pondicherry University, University of Delhi are now offering courses in PP at various levels, which was not popular a decade back. However, more rigorous effort is required in popularizing PP in India. Shahar (2013) points out that if this limited knowledge is not shared, more people shall not be interested in researching it and thus the building of empirical data base required to further the area will not take place. Conferences with themes of PP and well-being being regularly held across the country are contributing to spreading awareness. The National Positive Psychology Association also has been formed with the vision of enhancing PP research. NIMHANS, a prominent mental health institution in India has a Flourish Clinic and a Positive Psychology Unit along with Clinical Psychology and Psychiatry departments representing both the strengths based and medical approach to mental health. While Psychiatrist N. Nebhinani (personal communication, October 10, 2015) from AIIMS Jodhpur observes that most professionals are unaware of positive psychology and therefore do not use it in personal and professional practice, there is also evidence that some mental health professionals are beginning to incorporate PP in their practice. This was verified by Dr. M. Mehta (personal communication, October 12, 2015) from AIIMS Delhi who has experienced PP being "accepted and useful" in educational settings as well as psychiatrist N. Nebhinani who uses PP concepts occasionally during interactions with media, students (teaching and counseling), patients and at community lectures. Counselor M. Morris (personal communication, October 12, 2015) corroborates that many therapists are now realizing that PP can help clients especially with depression. She personally uses and sometimes also advises clients to maintain a gratitude journal. These along with the recent interest in positive psychiatry (Jeste, Palmer, Rettew, \& Boardman, 2015) indicate that steps toward building a PP community have been set in motion.

\section{Revisiting Seligman \& Csikszentmihalyi (2000)}

Seligman and Csikszentmihalyi (2000) had predicted a number of challenges that future positive psychologists would encounter and suggested future directions in which research endeavors were required. Attempts on answering some of these concerns have already been made. Researchers in India like Mehrotra (2014) and Rao (2014) propose studying concepts of IP and PP in combination to understand the mechanism of momentary happiness and lasting happiness for increasing long term well-being. Other questions like what governs happiness and well-being experiences through childhood have been answered by many studies on adolescents (Singh, Ruch, \& Junnarkar, 2014) and some on children (Holder, Coleman, \& Singh,
2012; Kapur, 2013). To prevent negative outcomes (e.g., depression) research is trying to understand character strengths and personality variables associated with happiness for example, Swaminath and Rao (2010). To answer whether a person can be happy despite the daily hassles of life, studies by Singh and Choubisa (2009a, 2009b) have used interventions while Peltzer and Pengpid (2013) have studied health behaviors and found that these interventions enable people to experience happiness in everyday lives. $\mathrm{PP}$ in India is still largely descriptive. Even though intervention studies are gaining popularity, they are still being tested and at some point of time we might be able to prescribe which interventions work best with which group. For example, it appears from evidence in the West that gratitude interventions have potential to work very well for those diagnosed with depression (McCullough, Emmons, $\&$ Tsang, 2002). To the best of our knowledge, no study in India has attempted understanding genetic determinants of positive traits. Mehrotra (2014) observes that, specifically within India, PP research needs to adopt critical thinking instead of imitating western methods, remove false beliefs surrounding PP, focus on application-based teaching methods and have forums for discussions among spiritual thinkers and practitioners. In this manner, an empirical base is slowly being built which will with time lead to building the PP community that Seligman had envisioned.

\section{Future Directions and Implications}

On the basis of the present review, some gaps in the literature have been identified and future directions and implications are being suggested accordingly. This section highlights areas which may be considered by future researchers. These include conducting research on topics that have not received adequate attention, making efforts to bridge the gap between IP and PP, addressing cultural issues in PP research, focusing on inter-disciplinary and multi-method approach and finally making PP available to the common people.

1. An understanding of areas which have been popularly studied such as resilience and life satisfaction has been gained from this review. While research on topics such as interventions, grit, posttraumatic growth, some character strengths, positive health and positive psychotherapy has taken place, more studies are needed for a better understanding of these phenomena in the Indian population. Topics such as hope and optimism have been studied but not under the ambit of the PP movement. Areas in which inconclusive findings have been reported such as personality factors and happiness among children, and meaningfulness and happiness 
should be re-investigated. It may be noted that no studies on some character strengths such as "love of learning," "bravery," and "prudence" were found. To begin with, future researchers may consider exploring these topics in contexts that are most relevant. For instance, love of learning in students, bravery in leaders and prudence among employees. Similarly, goal setting and goal pursuit in adolescents, work-life balance in older adults and social-connectedness among the geriatric population can be explored as contributors to well-being. Development of samplespecific tools should also be considered important. For example, the Personal Goal Survey (Rao \& Mehrotra, 2010) is in the process of being developed for different populations. PP research in clinical practice and organizational behavior may also be considered as priority areas. Other reviews focusing on particular PP variables like gratitude may be useful as these have been found to contribute greatly to well-being; however, these evidences are yet to be summarized in the Indian context.

2. Culturally appropriate investigations that study phenomena typical to our socio-cultural setup including relationships within the Indian family system such as authoritarian parenting styles, religion and caste system and teacher-student relationships which are very different from their Western counterparts should be explored in the context of PP variables. Pandey (2011) agrees that it may be inappropriate to use western notions of behavior interpretation for understanding the cognitions and actions of other indigenous cultures including India, China, and Arabia. Consideration of unique cultural components might result in Indian adaptations of PP concepts. For instance, an Indian version of values similar to PsyCap that can promote performance flourishing and well-being in the work place can be developed for our workplaces. Such efforts will help to encounter issues such as lack of generalizability of findings from the West due to cultural differences. For example, it may be pointed out that the character strengths of "gratitude" and "kindness" reveal themselves in very different ways within India. Overt expression of gratitude in close relationships is not expected in the Indian culture. Similarly, kindness intervention techniques like "random acts of kindness" which has been linked to increase in well-being levels in the West, might not be very effective across all sections of the Indian society particularly poverty stricken groups where people do not have much to give. In this sense, PP movement is still for the "elite." The PP movement had started in the West and most of the established theories are based on Western models and findings. This is supported by
Christopher (2014), Cornelissen (2014) and Misra (2014). Many studies simply follow trends set in the West; in this context, we agree with Mehrotra and Tripathi (2011) that PP research in India lacks "critical perspective." This could be because PP concepts like well-being are being accepted as universal as they were meant to be when originally proposed. But these concepts may manifest themselves differently under various cultural contexts as cited earlier. The kaleidoscopic nature of Indian behavior influenced by different regions, cultural norms and percolation of western thought processes in everyday life requires diverse lenses and continuous research to understand its patterns fully, specifically in intervention development. This is highlighted by researches which display differences in the factor structure of VIA, personality factors influencing well-being and importance of social relationships in life satisfaction in Indian samples. Along with these, we also need to bridge the gap between IP and PP. Concepts and models that can be useful for PP can be found in various Indian texts (Mehrotra 2014). Data mining of this knowledge base needs to be carried out to learn or re-learn what is already known about human nature and well-being in IP. This view is supported by Christopher (2014), Mehrotra (2014), Paranjpe (2014) and Rao (2014). Pandey (2011) recommends the need to build a culturally embedded PP. But we would like to caution researchers that we should not expect to build a distinct Indian PP. Like every other sub-discipline in psychology, the growth of PP will also be shaped by Indian as well as western influences.

3. Future researches need to have a multi-disciplinary view of PP in conjugation with disciplines that are closely linked to human behavior. This will provide an overall perspective of the PP concepts. For example, governmental policies, behavioral economics, neuroscience, genetics of happiness, and sociology need to be researched in more detail. Lyubomirsky, Sheldon and Schkade (2005) discovered that $50 \%$ of our happiness is genetically predetermined. A serotonin transporter gene has been associated with SWB (De Neve, 2011). To the best of our knowledge, no study in India has tried to examine the genetic determinants of happiness. Thus, future researchers need to plan how PP could be studied in combination with other areas for a better overall understanding of its concepts.

4. The sample, tools, and design of future studies should be considered carefully. More of qualitative, longitudinal, and cross-cultural analysis needs to be attempted. Longitudinal studies spanning over a year have not been attempted according to our review. Also, there is a need for research on populations other than 
university students and also on larger samples. Certain samples have so far been ignored. For instance, there is no research specifically studying males, very little focus on the geriatric population and relatively marginalized groups of people who may be suffering from undiagnosed psychological distress. Hence, future researchers need to look at these less studied samples.

5. Despite increasing awareness about psychological disorders with time where depression has become a household word, PP as a discipline is still limited largely to academic circles. Singh (2015) (http://www. ippanetwork.org/sippa/kamlesh-singh/) reasons that the linguistic and cultural diversity of the nation makes it difficult to take PP to the masses. Future researchers should also attempt to develop programs that make PP available to all. In this internet era, free sharing of information makes the possibility of spreading awareness about PP higher than ever before. Thus, PP can be made available to a section of the population with access to such technological devices through mobile text messaging, applications and websites. The first technique has reported favorable results for assessment, prevention, and promotion of mental health in urban slums in India (Chandra, Sowmyaa, Mehrotra, \& Duggal, 2014). Future researchers may consider testing this non-Internet-based technique in PP studies as well.

Counselor M. Morris shares that very often, most of the clients she has seen ultimately want to be happy. This should serve as an important reason to incorporate PP in therapy. Recently, few people in India including celebrities have publicly accepted their struggles with mental health issues. Such revelations will possibly raise awareness and encourage people to approach specialists that may help to remove the stigma that is still associated with it. This along with the suggestions provided here will build a PP community which is one of the major objectives of PP.

\section{Limitations of this Study}

This was originally attempted as a systematic review but while collecting the gray literature it was found that lack of databases that cover Indian publications filtered out some of the important contributions to the field done in India. Therefore, a general review was conducted to be able to incorporate these studies. However, a systematic review or meta-analysis would have yielded more concrete results. This study addressed a very specific question wherein only studies linked to PP have been included, omitting other researches on positive constructs that have not been specified to be connected to PP (for a more inclusive review, see Mehrotra \& Tripathi, 2011). Similarly, the focus on papers published only in English may have resulted in exclusion of work available in other languages. Additionally, most of the studies found were conducted using university/college students as samples; hence, there is a possibility that the conclusions drawn provide only a part of the bigger picture.

\section{Conclusions}

This paper has attempted to bring together those studies that have been inspired after the PP movement to build its knowledge base. From the available information, it can be derived that psychology research in India has started considering prevention as being equally important as cure. This exercise has revealed topics studied, methods used and gaps in the literature that need to be addressed in future. While topics like resilience have enjoyed popularity in research both within and outside PP contexts, certain constructs such as flourish, grit, character strengths of perseverance, kindness, forgiveness and the like, need more investigations without blindly replicating studies from the West. Also, exploration of constructs such as love, hope, and love of learning which have not yet generated a lot of research globally should be pursued in the Indian cultural context. Concepts such as spirituality, leadership, creativity, social intelligence, and humor have been popular topics of investigation but have not been linked to character strengths as proposed in the PP movement, and therefore according to the aim of the current review have not been discussed here. Well-being has both social and political importance (Miret et al. 2012) and as Seligman (2011) describes is the ultimate aim of positive psychology. Thus in future, various PP concepts need to be studied with an objective of contributing to well-being through multi-disciplinary approaches. Concrete steps need to be initiated by not only researchers but also policy makers to ensure that these research findings reach the wider population. It is expected that this review will bring about more awareness about the area, its current status and promote research on the priority areas identified here. Conducting another review in some years might be useful in systematically mapping the progress of PP in India. Finally, it may be concluded that PP research provides exciting new possibilities that can be tapped into for PP to flourish in India.

Acknowledgments The authors would like to thank researchers for sharing their publications via e-mail communication and to the anonymous reviewers for their suggestions. The current work has been undertaken by the funding provided by Indian Council of Medical Research. 


\section{References}

Banavathy, V. K., \& Choudry, A. (2014). Understanding happiness: A vedantic perspective. Psychological Studies. doi:10.1007/ s12646-013-0230-x.

Banerjee A (2013) Work pressure pushing techies to the brink. The Times of India. Retrieved from: http://timesofindia.indiatimes. com/india/Work-pressure-pushing-techies-to-the-brink/article show/21926233.cms

Bhushan, B., \& Kumar, J. S. (2012). A study of posttraumatic stress and growth in tsunami relief volunteers [Abstract]. Journal of Loss and Trauma: International Perspectives on Stress \& Coping. doi:10.1080/15325024.2011.635580.

Bhushan, B., Kumar, S., \& Harizuka, S. (2011). Bereavement, cognitive-emotional processing, and coping with the loss: A study of Indian and Japanese students [Abstract]. Journal of Social Work in End-of-life and Palliative Care. doi:10.1080/ 15524256.2011.593160.

Biswas-Diener, R., \& Diener, E. (2001). Making the best of a bad situation: Satisfaction in the slums of Calcutta. Social Indicators Research, 55, 329-352.

BS Reporter (2014). Suicide rate highest among youngsters in India: WHO. Business Standard. http://www.business-standard.com/ article/current-affairs/suicide-rate-highest-among-youngsters-inindia-who-114090400879_1.html. Accessed February 9, 2015.

Campbell- Sills, L., \& Sills, M. B. (2007). Psychometric analysis and refinement of the Connor-Davidson Resilience Scale (CDRISC): Validation of a 10-item measure of resilience. Journal of Trauma and Stress. doi:10.1002/jts.20271.

Chandra, P. S., Sowmyaa, H. R., Mehrotra, S., \& Duggal, M. (2014). 'SMS' for mental health-Feasibility and acceptability of using text messages for mental health promotion among young women from urban low income settings in India [Abstract]. Asian Journal of Psychiatry. doi:10.1016/j.ajp.2014.06.008.

Chatterjee, P. (2011). Study says India most depressed country. Indian Express. Retrieved from: http://archive.indianexpress. com/news/study-says-indiamost-depressed-country/822950/. Accessed 9 Feb 2015.

Choubisa, R. (2011). Enhancing college students' well-being through a web-based intervention module: An empirical investigation. Unpublished Doctoral Dissertation, Indian Institute of Technology Delhi New Delhi.

Choubisa, R., \& Singh, K. (2011). Psychometrics encompassing VIAIS: A comparative cross cultural analytical and referential reading. Journal of the Indian Academy of Applied Psychology. https://www.academia.edu/692564/Psychometrics_Encompass ing_VIA-IS_A_Comparative_Cross_Cultural_Analytical_and_ Referential_Reading. Accessed September 3, 2014.

Christopher, J. C. (2014). Putting "positive" and "psychology" in perspective: The role of Indian psychology. Psychological Studies. doi:10.1007/s12646-014-0249-7.

Cornelissen, R. M. M. (2014). A commentary on "Positive psychology and Indian psychology: In need of mutual reinforcement". Psychological Studies. doi:10.1007/s12646-014-0248-8.

Cummins, R. A., \& Lau, A. L. D., (2005). Personal wellbeing indexSchool children (3rd edn). http://www.deakin.edu.au/research/ acqol/instruments/wellbeing-index/pwi-id-english.pdf. Accessed September 3, 2014.

Dalal, A. K. (2014). Search for grounds of mutual reinforcement. Psychological Studies. doi:10.1007/s12646-014-0255-9.

De Neve, J. (2011). Functional polymorphism (5-HTTLPR) in the serotonin transporter gene is associated with subjective wellbeing: Evidence from a US nationally representative sample. Journal of Human Genetics. doi:10.1038/jhg.2011.39.
Diener, E. (1984). Subjective well-being. Psychological Bulletin, 95(3), 542-575.

Donaldson, S. I., Dollwet, M., \& Rao, M. A. (2014). Happiness, excellence, and optimal human functioning revisited: Examining the peer-reviewed literature linked to positive psychology. The Journal of Positive Psychology: Dedicated to Furthering Research and Promoting Good Practice. doi:10.1080/ 17439760.2014.943801.

Donaldson, S. I., \& Ko, I. (2010). Positive organizational psychology, behavior, and scholarship: A review of the emerging literature and evidence base. The Journal of Positive Psychology. doi:10. 1080/17439761003790930.

Fredrickson, B. L. (1998). What good are positive emotions? Review of General Psychology, 2(3), 300-319. doi:10.1037/1089-2680. 2.3.300.

Gupta, V., \& Singh, S. (2014). Psychological capital as a mediator of the relationship between leadership and creative performance behaviors: Empirical evidence from the Indian R\&D sector. The International Journal of Human Resource Management. doi:10. 1080/09585192.2013.870311.

Hafen, C. A., Singh, K., \& Laursen, B. (2011). The happy personality in India: The role of emotional intelligence. Journal of Happiness Studies, 12, 807-817. doi:10.1007/s10902-010-9228-4.

Hasnain, N., Khan, O., Hasan, Z. (2013). Organizational citizenship behavior, happiness and work motivation as correlates of organizational commitment of managers of public and private banks. The International Journal of Humanities \& Social Studies. http://theijhss.com/3.HSS1309-007.pdf. Accessed August 25, 2014.

Hills, P., \& Argyle, M. (2002). The Oxford Happiness Questionnaire: A compact scale for the measurement of psychological wellbeing. Personality and Individual Differences, 33, 1073-1082.

Holder, M. D., Coleman, B., \& Singh, K. (2012). Temperament and happiness in children in India. Journal of Happiness Studies. doi:10.1007/s10902-011-9262-x.

Hussain, D., \& Bhushan, B. (2013). Posttraumatic growth experiences among Tibetan refugees: A Qualitative Investigation [Abstract]. Qualitative Research in Psychology. doi:10.1080/14780887. 2011.616623.

Jesson, J. K., Matheson, L., \& Lacey, F. M. (2013). Doing your literature review: Traditional and systematic techniques. New Delhi: Sage Publications India Pvt. Ltd.

Jeste, D. V., Palmer, B. W., Rettew, D. C. \& Boardman, S. (2015). Positive psychiatry: Its time has come. The Journal of Clinical Psychiatry, 76(6), 675-683. http://www.psychiatrist.com/JCP/arti cle/_layouts/ppp.psych.controls/BinaryViewer.ashx?Article=/JCP/ article/Pages/2015/v76n06/v76n0601.aspx\&Type=Article.

Kapur, M. (2013). Resilience and competence in childhood. In G. Misra (Ed.), History of science, philosophy and culture in indian civilization, 13(3) (pp. 255-267). New Delhi: Munshiram Manoharlal Publishers Pvt. Ltd.

Khosla, M., \& Dokania, V. (2010). Does happiness promote emotional intelligence? Journal of the Indian Academy of Applied Psychology, 36(1), 45-54.

Kumar, A., \& Kumar, S. (2013). Karma yoga: A path towards work in positive psychology. Indian Journal of Psychiatry. doi:10.4103/ 0019-5545.105511.

Lakshmanan, R. M. K., \& Mythili, T. (n. d.). The effect of psychological intervention on resilience among early adolescent girls in Chennai corporation school. http://counselingchennai. com/yahoo_site_admin/assets/docs/Full_paper_Resilience_ Study.22205430.pdf. Accessed Dec 15, 2014.

Linley, P. A., \& Harrington, S. (2006). Strengths coaching: A potential-guided approach to coaching psychology. International Coaching Psychology Review. http://groups.psychology.org.au/ 
Assets/Files/ICPR_journal_1_April_2006.pdf\#page=39. Accessed August 14, 2014.

Linley, P. A., \& Leontiev, D. (2009). Multiple dimensions of the good life: Introducing international and interdisciplinary perspectives. The Journal of Positive Psychology. doi:10.1080/ 17439760902933641.

Lopez, S. J. (2009). Encyclopedia of positive psychology. United Kingdom: Wiley.

Lyubomirsky, S., King, L., \& Diener, E. (2005a). The benefits of frequent positive affect: Does happiness lead to success? Psychological Bulletin. doi:10.1037/0033-2909.131.6.803.

Lyubomirsky, S., \& Lepper, H. (1999). A measure of subjective happiness: Preliminary reliability and construct validation. Social Indicators Research. http://sonjalyubomirsky.com/subjec tive-happiness-scale-shs. Accessed March 2, 2015.

Lyubomirsky, S., Sheldon, K. M., \& Schkade, D. (2005b). Pursuing happiness: The architecture of sustainable change. Review of General Psychology. doi:10.1037/1089-2680.9.2.111.

Magesh, P., Shruthi, \& Divya (2014). A study on relationship between forgiveness, gratitude and subjective well-being among adolescents. The International Journal Of Humanities \& Social Studies. http://theijhss.com/force_download.php?file_path=wpcontent/uploads/2015/03/2.HS1409-114.pdf\&id=839. Accessed December 20, 2014.

Malik, A., \& Singh, D. (2012). Happiness: A central objective of positive psychology. Indian Journal of Positive Psychology. doi:10.15614/ijpp/2012/v3i1/49779.

Mathur, R., \& Sharma, S. (2014). A correlational study of positive concomitants of well-being. IIS Unversity Journal of Social Science. http://iisjoss.org/sites/default/files/iisjoss/2014/PDF/ 3.\%20Roopa\%20Mathur\%20and\%20Swati\%20Sharma.pdf. Accessed December 5, 2014

McCullough, M. E., Emmons, R. A., \& Tsang, J. (2002). The grateful disposition: A conceptual and empirical topography. Journal of Personality and Social Psychology. doi:10.1037//0022-3514.82. 1.112

Mehrotra, S. (2013). Feeling good \& doing well?-Testing efficacy of a mental health promotive intervention program for Indian youth. International Journal of Psychological Studies. doi:10. 5539/ijps.v5n3p28.

Mehrotra, S. (2014). Synergy between positive psychology and Indian psychology? Reflections on barriers and pathways. Psychological Studies. doi:10.1007/s12646-014-0257-7.

Mehrotra, S., Elias, J. K., Chowdhury, D., \& Gupta, A. (2013). Feeling good \& doing well: Development of a mental health promotion program for youth. Psychological Studies. doi:10. 1007/s12646-012-0176-4

Mehrotra, S., \& Tripathi, R. (2011). Positive psychology research in India: A review and critique. Journal of the Indian Academy of Applied Psychology, 37(1), 9-26.

Mehrotra, S., \& Tripathi, R. (2013). Flourishing at work. In D. M. Pestonjee \& S. Pandey (Eds.), Stress and work: Perspectives on understanding and Managing Stress (pp. 239-263). New Delhi: Sage Publications.

Mehrotra, S., Tripathi, R., \& Banu, H. (2015). Assessment of character strengths: Preliminary report on a vignette based measure [Abstract]. Journal of the Indian Academy of Applied Psychology, 38(3), 151-160.

Meyers, M. C., Woerkom, M., \& Bakker, A. B. (2013). The added value of the positive: A literature review of positive psychology interventions in organizations. European Journal of Work and Organizational Psychology. doi:10.1080/1359432X.2012.694689.

Miret, M., Caballero, F. F., Mathur, A., Naidoo, N., Kowal, P., et al. (2012). Validation of a measure of subjective well-being: An abbreviated version of the Day Reconstruction Method. PLoS One, 7(8), e43887. doi:10.1371/journal.pone.0043887.
Misra, G. (2014). Editorial. Psychological Studies. doi:10.1007/ s12646-014-0263-9.

Mukherjee, S., Nargundkar, M., \& Manjaly, J. A. (2014). Monetary primes increase differences in predicted life-satisfaction between new and old Indian Institutes of Technology (IITs). Psychological Studies. doi:10.1007/s12646-014-0259-5.

Murthy, R. K. (2014). Psychological capital, work engagement and organizational citizenship behaviour. Department of Psychology, Osmania University, Hyderabad. http://nci2tm.sinhgad.edu/ NCIT2M2014_P/data/NCI2TM_72.pdf. Accessed September 2, 2014.

Nath, P., \& Pradhan, R. K. (2011). Positive writing and positive wellbeing: Issues and implications. Indian Journal of Health and Well-Being, 2(1), 61-64.

Nath, P., \& Pradhan, R. K. (2012). Influence of positive affect on physical health and psychological well-being: Examining the mediating role of psychological resilience. Journal of Health Management. doi:10.1177/097206341201400206.

Nath, P., \& Pradhan, R. K. (2013). Implications of positive emotions in growing out of adversity: Examining the role of individual differences. In Paper presented at 3rd biennial conference of the Indian Academy of Management. http://vslir.iimahd.ernet.in:8080/ xmlui/handle/123456789/11505. Accessed September 1, 2014.

Nath, P., \& Pradhan, R. K. (2014). Does feeling happy contributes to flexible thinking: Exploring the association between positive emotions and cognitive flexibility. Psychological Studies. doi:10. 1007/s12646-014-0241-2.

Pandey, S. (2011). Positive psychology: Blending Strengths of Western, Eastern and Other Indigenous Psychologies. In Paper presented at 1st international conference on "Emerging Paradigms in Business \& Social Sciences." http://papers.ssrn.com/ sol3/papers.cfm?abstract_id=2150585. Accessed December 2, 2014.

Pandit, S. A., \& Satish, L. (2014). When does yoga work? Long term and short term effects of yoga intervention among pre-adolescent children. Psychological Studies. doi:10.1007/s12646-013-0209-7.

Paranjpe, A. (2014). On getting best of both the worlds [Abstract]. Psychological Studies. doi:10.1007/s12646-014-0249-7.

Paul, H., \& Garg, P. (2014). Healing HRM through positive psychology: An outlook. Procedia-Social and Behavioral Sciences. doi:10.1016/j.sbspro.2014.04.178.

Peltzer, K., \& Pengpid, S. (2013). Subjective happiness and health behavior among a sample of university students in India. Social Behavior and Personality. doi:10.2224/sbp.2013.41.6.1045.

Pereira, I. (2013). India saw 1,35,445 suicides last year. The Hindu. http://www.thehindu.com/news/national/india-saw-135445-sui cides-last-year/article4849710.ece. Accessed February 9, 2015.

Peterson, C. (2007). Character strengths (chapter 6). A primer in positive psychology. (pp. 137-164). New Delhi: Oxford University Press.

Peterson, C., \& Seligman, M. E. P. (2004). Character strengths and virtues: A handbook and classification. Washington, DC: APA Press and Oxford University Press.

Pinjarkar, R., \& Mehrotra, S. (2014). Meaning in life and well-being in the lives of college going Indian youth. Journal of the Indian Academy of Applied Psychology. http://jiaap.org/Listing_Detail/ Logo/a5d8c6a5-ae6b-43b2-b606-96056c4c0a4b.pdf. Accessed December 5, 2014.

Pirta, R. S. (2014). Yoking gnosis and logos: On the knowledge function of some exceptional mental states for well-being. Psychological Studies. doi:10.1007/s12646-013-0210-1.

Pradhan, R. K., \& Nath, P. (2011). Dynamics of positive emotions and creative potential. Indian Journal of Positive Psychology, 2(1), 103-107.

PTI (2014, September 4). India has highest number of suicides in the world: WHO. The Economic Times. Retrieved from: http:// 
articles.economictimes.indiatimes.com/2014-09-04/news/ 53563875_1_suicide-attempts-suicide-rate-prevention. Accessed February 9, 2015.

Raje, M. (2014). Integrated psycho-therapeutic approach restores family mental health [Abstract]. European Psychiatry. doi:10. 1016/S0924-9338(14)77596-0.

Ramesh, M. G., Sathian, B., Sinu, E., \& Rai, K. S. (2013). Efficacy of Rajayoga meditation on positive thinking: An index for selfsatisfaction and happiness in life. Journal of Clinical and Diagnostic Research. doi:10.7860/JCDR/2013/5889.3488.

Rao, K. R. (2014). Positive psychology and Indian psychology in need of mutual reinforcement. Psychological Studies. doi:10. 1007/s12646-013-0228-4.

Rao, D., \& Mehrotra, S. (2010). Personal Goal Survey development and preliminary trial in the Indian community. Journal of the Indian Academy of Applied Psychology, 36(1), 133-145.

Rathi, N. (2011). Psychological well-being and organizational commitment: Exploration of the relationship. Working Paper No.106/2011. Amrita School of Business. https://www.amrita. edu/faculty/dr-neerpal-rathi. Accessed September 3, 2014.

Ridley, D. (2012). The literature review: A step-by-step guide for students (2nd ed.). New Delhi: Sage Publications India Pvt. Ltd.

Sahoo, F. M., \& Sahu, R. (2009). The role of flow experience in human happiness. Journal of the Indian Academy of Applied Psychology. http://medind.nic.in/jak/t09/s1/jakt09s1p40.pdf. Accessed September 3, 2014.

Salagame, K. K. (2014). Positive psychology and Indian psychology: Birds of the same feather. Psychological Studies. doi:10.1007/ s12646-014-0258-6.

Sankaranarayanan, A., \& Cycil, C. (2014). Resiliency training in Indian children: A pilot investigation of the PENN resiliency program. International Journal of Environmental Research and Public Health. doi:10.3390/ijerph110404125.

Seligman, M. E. P. (2002). Authentic happiness. London: Nicholas Brealey Publishing.

Seligman, M. E. P. (2011). Flourish: A new understanding of happiness and well-being - and how to achieve them. Boston: Nicholas Brealey Publishing.

Seligman, M. E. P., \& Csikszentmihalyi, M. (2000). Positive psychology: An introduction. American Psychologist. doi:10. 1037/0003-066X.55.1.5.

Seligman, M. E. P., Steen, T. A., Park, N., \& Peterson, C. (2005a). Positive psychology progress. American Psychologist. doi:10. 1037/0003-066X.60.5.410.

Seligman, M. E. P., Steen, T. A., \& Peterson, C. (2005a). Positive psychology progress: Empirical validation of interventions. American Psychologist. http://www.ppc.sas.upenn.edu/ppprogres sarticle.pdf.

Shahar, T. B. (2013). Happiness 101. TED talks. Retrieved from https://www.youtube.com/watch?v=OxsPl2WClHg.

Shahnawaz, M. G., \& Jafri, M. H. (2009). Psychological capital as predictors of organizational commitment and organizational citizenship behaviour. Journal of the Indian Academy of Applied Psychology. http://medind.nic.in/jak/t09/s1/jakt09s1p78.pdf. Assessed October 16, 2014.

Sharma, C., \& Choudhary, A. (2013). Positive psychology: An approach to rehabilitation of trafficked victims. International Journal of Scientific and Research Publications. http://www. ijsrp.org/research-paper-0813.php?rp=P201622\#citatio. Accessed November 5, 2014.

Shrivastava, A. K., \& Misra, G. (2011). Happiness and well-being: An Indian perspective. In G. Misra (Ed.), Handbook of psychology in India (pp. 299-310). New Delhi: Oxford University Press.

Singh, K. (2010). Positive psychology and its intervention programmes for academic institutes. Psychosocial Aspect of Health and Illness. http://globalvisionpub.com/globaljournalmanager/ pdf/1390387658.pdf. Accessed December 19, 2014.

Singh, K. (2015). Professor spotlight: Kamlesh Singh, Ph.D. (SIPPA, Interviewer). International Positive Psychology Association. Retrieved from: http://www.ippanetwork.org/sippa/kamleshsingh/. Accessed 7 Sep 2016.

Singh, K., \& Choubisa, R., (2009a). Psychometric properties of Hindi translated version of values in action inventory of strengths (VIA-IS). Journal of Indian Health Psychology. https://www. academia.edu/631337/Psychometric_properties_of_Hindi_trans lated_version_of_Values_in_Action_Inventory_of_Strengths_ VIA-IS_. Accessed November 19, 2014.

Singh, K., \& Choubisa, R. (2009b). Effectiveness of self focused intervention for enhancing students' well-being. Journal of the Indian Academy of Applied Psychology. http://medind.nic.in/jak/ t09/s1/jakt09s1p23.pdf. Accessed October 16, 2014.

Singh, K., \& Choubisa, R. (2010). Empirical validation of values in action-inventory of strengths (VIA-IS) in Indian context. Psychological Studies. doi:10.1007/s12646-010-0015-4.

Singh, K., \& Duggal, S. (2012). Relationship between values in action and personality factors: A positive psychology perspective [Abstract]. Indian Journal of Clinical Psychology, 36(1), 33-41.

Singh, K., \& Jha, S. D. (2008). Positive and negative affect, and grit as predictors of happiness and life satisfaction. Journal of the Indian Academy of Applied Psychology, 34(Special Issue), $40-45$.

Singh, K., Kaur, J., Singh, D., \& Junnarkar, M. (2014a). Sociodemographic variables affecting well-being: A study on Indian rural women. Psychological Studies. doi:10.1007/s12646-0140239-9.

Singh, K., Ruch, W., \& Junnarkar, M. (2014b). Effect of the demographic variables and psychometric properties of the personal well-being index for school children in India. Child Indicators Research. doi:10.1007/s12187-014-9264-4.

Singh, A. K., Singh, S., \& Singh, A. P. (2012). Does trait predict psychological well-being among student of professional courses? Journal of the Indian Academy of Applied Psychology, 38(2), 234-241.

Singh, K., \& Yu, X. (2010). Psychometric evaluation of the ConnorDavidson Resilience Scale (CD-RISC) in a sample of Indian students. Journal of Psychology, 1(1), 23-30.

Sood, S., \& Gupta, R. (2012). A study of gratitude and well being among adolescents. IOSR Journal of Humanities and Social Science. http:// figshare.com/articles/A_study_of_gratitude_and_well_being among_adolescents/1270172. Accessed November 15, 2014.

Swaminath, G., \& Rao, B. R. R. S. (2010). Going beyond psychopathology-positive emotions and psychological resilience. Indian Journal of Psychiatry. doi:10.4103/0019-5545.58887.

Thirunavukarasu, M., \& Thirunavukarasu, P. (2010). Training and national deficit of psychiatrists in India-A critical analysis. Indian Journal of Psychiatry. http://www.indianjpsychiatry.org/ article. asp? issn $=0019-5545 ;$ year $=2010$; volume $=52 ;$ issue $=7$; spage $=83$; epage $=88$; aulast $=$ Thirunavukarasu. Accessed February 20, 2015.

Watson, D., Clark, L. A., \& Tellegen, A. (1988). Development and validation of brief measures of positive and negative affect: The PANAS Scale. Journal of Personality and Social Psychology. doi:10.1037/0022-3514.54.6.1063.

World Health Organization (2014). Retrieved from: http://www.who. int/en/.

Yadav, R., Koushal, V., Aggarwal, P., Saini, V., \& Sharma, R. (2012). The interrelationship between positive mental and physical health: A health promoting approach. Indian Journal of Positive Psychology, 3(1), 47-52. 